\title{
The 'interrogative gaze'
}

\section{Making video calling and messaging 'accountable'}

\author{
Richard Harper, Sean Rintel, Rod Watson and Kenton O'Hara \\ Social Shaping Research, Cambridge / Microsoft Research, Cambridge / \\ Telecom ParisTech, Nice-Sophia-Antipolis / University of Bristol, Cambridge
}

This paper identifies salient properties of how talk about video communication is organised interactionally, and how this interaction invokes an implied order of behaviour that is treated as 'typical' and 'accountably representative' of video communication. This invoked order will be called an interrogative gaze. This is an implied orientation to action, one that is used as a jointly managed interpretative schema that allows video communication to be talked about and understood as rationally, purposively and collaboratively undertaken in particular, 'known in common' ways. This applies irrespective of whether the actions in question are prospective (are about to happen) or have been undertaken in the past and are being accounted for in the present or are 'generally the case' - in current talk. The paper shows how this constitutive device also aids in sense making through such things as topic management in video-mediated interaction, and in elaborating the salience of the relationship between this and the patterned governance of social affairs - viz, mother-daughter, friend-friend - as normatively achieved outcomes. It will be shown how the interrogative gaze is variously appropriate and consequentially invoked not just in terms of what is done in a video call or making such calls accountable, but in helping articulate different orders of connection between persons, and how these orders have implications for sensible and appropriate behaviour in video calling and hence, for the type of persons who are involved. This, in turn, explains how a decision to avoid using video communication is made an accountably reasonable thing to do. The relevance of these findings for the sociology of everyday life and the philosophy of action are explored.

Keywords: video calling, video mediated communication, Skype, conversation analysis, ethnomethodology, sociology, philosophy of action, family, friendship, participation frameworks, reasoning 


\section{Introduction}

Some words seem to evoke an era, resonant not just of the argot of everyday chitchat but also the fixations and practices of a cultural moment. Skyping is one of those words. Already it is losing its sheen as alternative technologies muddle its role in vernacular language: Facetime, Google Hangouts, as well as nouns for other communications media - WhatsApp, Instagram - crowd into everyday parlance and, even as we write, Skyping is beginning to sound outmoded, past, echoing what is turning out of fashion. The world is constantly changing, after all, and much of this has to do with the evolving landscape of technology. But nevertheless, Skype is in practice a denotation for all types of video communication, like Xerox came to be for photocopying, and just as Xerox the company receded in importance, so too, perhaps, is Skype - but people still use that word to label all kinds of video calling, whatever the brand or supplier.

That's as may be. But one of the curiosities of language is that it allows people to label actions and describe behaviours in ways that imply that the words used are sufficient to comprehend what is being evoked and yet, as Wittgenstein noted in his Philosophical Investigations (1953), to understand what is meant by some word or phrase necessitates knowing something already about the life in question, about the doings labeled by the words. So it is with Skype. To ask why someone makes a Skype call is not to label an activity that is yet to be properly described or understood by the people posing the question. Someone does not make this query because they do not know what Skype means. The question is asked because they want to know why some individual would behave in some particular way given what Skype action is already known to be. They are enquiring into the fitting of individual purposes and actions into the technologically mediated circumstances at hand. To Skype is part of a form of life that is already understood, engaged in as a normal feature of human affairs - in contemporary patterns of friendship and family, part of being 'in touch' when being in touch is the thing to do. To Skype is to inhabit familiar territory, familiar because it has been learnt to the level of being taken for granted.

If the use of the word 'Skype' is anything to go by, then words have a complex relationship with the activities they are bound to and denote. Part of this complexity has to do with how their use foregrounds certain types of orientations to the activities in question where other things about those activities are kept as background features such that they can be presupposed, assumed, to an extent ignored. As we say, to ask why someone Skypes may not be about Skype in general, what is routinely presumed in the doing of it, but about the particularities being articulated in that specific Skype call. These may have something to do with what is relevant to the persons involved; as a case in point, that they may be friends say, something to do with family connection, or related to courting perhaps - seeing as a way of loving 
comes to mind. In these respects, there are, one imagines, an almost infinite number of possible answers to the question, 'Why Skype?' It depends on the circumstances. And one would expect as well that these will be made up of the diverse and complex trajectories of human connection (Ingold 2011) made manifest in chosen courses of action in which mediated communication has a role - and there are, one need hardly add, presumably very many of these.

To this extent, the deployment of a word like 'Skype' is a gloss for all types of video connection. Using such a gloss is not, we are saying, a way of labeling an activity; it is to marshal stocks of knowledge about the doings of the world that enables the constituting of observed acts through the use of that word in common language and talk. One should not forget either that, in being used in talk, doing so also indexes a stock of knowledge to be brought to bear collaboratively - through the turns of talk in which the gloss is used. To talk about Skype is to make an interpretative scheme through which a world in common that has Skype as a feature is both produced and shared. To put it another way, to ask why someone Skypes is to formulate through language how to see the world such that understandings about certain types of behaviour and intentional stances typically and ordinarily deployed in activities related to that term can be used as a resource to make sense of particular actions at hand or in the offing. The ordinary world, so to speak, is in a word, even if that word may seem to be losing its general valence, its fashionability, as may be the case with Skype.

\section{Approach to evidence}

We present this preamble as a way of emphasising the analytical perspective we want to take in this paper. As should be already clear, we are less interested in technology in itself, in how something like Skype works (or its proxies, Facetime, Google Hangouts and the rest, often rather charmlessly described through an acronym, VMC, Video Mediated Communication) or in how such technologies might be described by, say, marketing and technology vendors; we are much more concerned with the reasoning and other practices that are constitutive of, and thus productive of, everyday life. More especially we are interested in the ways in which language use is part of the life in which technology is brought into play. In our view, it is in the organisation of language that technology gets to be made a socially relevant and shaped phenomenon. In these respects, our concern echoes, in varying degrees and ways, ethnomethodology (Garfinkel 1967), conversation(al) analysis and membership categorization analysis (Maynard 1988; Fitzgerald and Housley 2015). These approaches variously focus on how ordinary society is, in various ways, incarnate in talk. 
The move to a concern for language use has important implications for the kinds of evidence that can be brought to bear on investigation as well as in regard to the analytic statements and insights that can be generated from it. All this is worth bearing in mind if one wants to take this approach in one's own research, as we do in this paper.

To begin with, this approach opens up where data can be found. For, in this view, it can be found in any type of talk about Skype as well as in the talk one can observe when people are Skyping; when talk is in vivo if you like. As we have noted, talk about Skype (and indeed other video mediated communications channels that the word labels) always and multifariously invokes a world known in common and a world in which 'know-how' about what Skype entails, what it implies, and why it is used, is deployed as part of the sense-making procedures embedded in interaction. Through knowing about what Skype entails, people can come to some intersubjective agreement about what they are doing at any particular moment in time, planning a Skype call, for example, accounting for a Skype call that has happened, or talking about Skype to an interviewer. Ways of investigating Skype are then quite open in this view: there is no need to fix observed behaviours to moments when Skype is 'on'; one simply needs to examine the utterances of everyday life in which Skype is brought up and, on occasion, used (or to use Sacks and Schegloff's (1979) phrase, becomes a 'mentionable', or what Adato (1980) terms an 'occasioned topic'). One needs ordinary life, in other words; ordinary talk. The data presented later on in this paper is of this order - though elicited in the open-ended setting of interviews, our analysis is of how Skype and Skyping is brought to bear in ordinary ways in this fabricated social encounter.

Second, and as has been explained in the introduction of this Special Issue of Pragmatics, the tenor of sociological inquiry into video-mediated communication generally focuses on explanations that point towards how that use satisfies some generalisable characteristic of society. As a case in point, Madianou and Miller argue in Migration and New Media (2012) that transnational economic migration needs technologies that enable the fabric of family structures to be sustained. Modern society needs migrator workers, workers need families, therefore workers need video connections if they are to continue being functioning members of those families. Even if it is the whole nuclear or semi-extended family that migrates or simply the parents, say, the remaining family can be connected, 'made real', via video connection, via Skype. Certainly this is what Madianou and Miller assume. Having taken this perspective, however, the reasoning of the human at the centre of this connection between the doings of economic action and the doings of family life is not the main subject of such inquiries. That people will reason in accord with these perceived social needs and, for example, match Skype to migration is a given; that they become users, migrant users of Skype in Madianou and Miller's 
phraseology, is because they have to. Modern society makes it so. It causes them to act thus (for a similar argument also see Miller \& Sininan, 2014). ${ }^{1}$

The approach we take here has a quite different view of the reasoning of people, though, not only making it much more the focus of concern but in wanting to explore how it is done as a practical matter for those doing it. And key to this perspective is taking mundane language use, talk most especially, as a site of important work, for this approach treats language as the vehicle for the reasoning of persons as a collaborative practice, as something done together, in their particular, situated interaction. In this view, spoken self-understandings, articulations about someone's social connections and patterned ways of communicating, come to be the material basis of intersubjective understanding for those involved, others as well as the self; they also become sources of the experiential shape of that world as constituted by an arrangement of intersecting, accountable human intentions. In this respect, talk and how it is part of action is, as Garfinkel memorably put it (1967), a members problem insofar as talk and its intertwining with action is what ordinary people have to attend to in their daily affairs, in their chit-chat about, as in this case, being in touch just as it is in those acts of being in touch (Harper 2011). Talk is part of the stuff of their reasoning in other words and, hence, in this case, it is very much part of their ordinary reasoning about video communication such as Skype that is of interest to us.

For us, then, what 'causes' people to use video communication on particular occasions is not primarily an analytic matter involving a specialist use of the term cause. Instead, we address ourselves toward users' own ordinary employment of that term (viz, 'cause') in their accounting of, say, a particular instance of video communication to their family back in the home country. They may tell us, unprompted, about "what caused them to Skype" on "this occasion". We treat their causal mputation as a datum to be explicated and explored as a topic in its own right, where their management and deployment of terms like 'cause' are tools in their sense making procedures. In this sense, we are not setting up the kind of analysis which naturalistic researchers of various stripes term methodological irony; that is, an analysis that seeks to compete with or contest with the reasons that people own and articulate. We do not want to downgrade or even supplant their reasons for

1. Of course, there are problems attached to this analytic use of 'cause'. As the philosopher Hanson noted long ago (1972), there have been numerous semantic and pragmatic changes in the way the term has been used and even the most systematic and thorough investigations end up acknowledging that such a term can be slippery. As Hume showed two centuries before Hanson, cause often describes some event in explaining it ([1739-40] 1974), begging the value of the concept of cause as something unique and separate from understanding. For the kinds of relations that Madianou and Miller are after, such looseness is acceptable but see Harper et al. 2016, 197-214. 
Skyping and replace them with our own. Instead we take ordinary people and their reasoning - in this case, ordinary 'Skypers' and their reasons - as our evidential starting point. We try to consider their reasons for using Skype as part and parcel of a weave of practices of mundane reason that constitute 'Doing Skyping' as part of their ordinary routines and practices. Like Papacharissi (2011), though her topic is another form of mediated communication, social networks, we think that how people choose to act in and through technology and indeed how they talk about it is their business; in our view it ought to be ours too.

That this is so has another and perhaps equally important consequence: though an individual may have little knowledge of how the technology of video communication (or indeed other related technologies) might work, their adroit use of interactional technique and know-how when they talk about and use that technology makes their skills at doing so more salient to analytical inquiry about the nature of the technology as a social phenomenon than any expertise about the technology itself. Being skilled at acts of communication, being astute at choosing between different technologies of communication, and applying all this know-how effectively in what one might call the politics of friendship and family (or anything else they might do with Skype), is not ordinarily labeled with educational certificates or professional affiliation - one does not need to be a communications engineer to use Skype properly. One needs to be a competent member of society, one who knows what is meant when someone says "Let's Skype". It's not the ability to switch on a computer and find the application that is at issue, for these are a given; it is a gloss for knowing why a Skype call is a reasonable thing to do. ${ }^{2}$

And here is the rub of the matter for us, the target of our research. In our view, such a concern is central (though not exclusive) to enquiries into social order and how this is manifest in everyday, mundane, ordinary action. Here we see how reasoning practices in situ are constitutive of that order. This is certainly not the only way one can inquire into social order, but is clearly crucial to such enquiries (Garfinkel \& Sacks 1970). Such inquiries will be of interest to the pragmatics community just as they will be to sociology more generally.

But they will also be of interest to the philosophy of action. This perspective is likewise concerned with what ordinary reasons might be and how they operate in and through human practices. For the past twenty or thirty years, one general opinion in this area of philosophy has been that reasons are causes, albeit that the range of these reasons and their role as causal requires specification that is often

2. Of course, this is a new version of an old phenomenon: one does not need to know about the chemical composition of the metal out of which a knife and fork are fashioned in order to use them competently in eating one's dinner, say, in the co-presence of fellow diners. Norbert Elias explores this in his seminal The Civilizing Process (1969). 
disputed, and often as well conflating important distinctions (for a background see Leist 2007; for the perspective of sociology on these debates see Harper et al. 2016, 197-235). These difficulties are bound up in part with the subtle character of the term itself and how it has evolved, though they are more importantly a reflection of the diverse ways that reasons are invoked in language use. Language praxis is untidy, diverse and at times ragged; complex too in ways that makes reasons articulated through language acts complex and subtle. That this is so has resulted in the consensus about reasons as causes being replaced by a more pluralistic perspective within the philosophy of action, where reasons can have many forms and roles, causal being only one. In this manner some of the many conflations that muddle arguments in the area can be avoided, some believe (see most especially Sandis 2012). In our view, recognition of these difficulties, bound as many are to language, is a roundabout way of allowing some of Wittgenstein's (1953) insights into language to gain favour again (Harper et al. 2016), for these very complications were the central topics of his later enquiries. ${ }^{3}$ At the same time, it allows a sociological view on the empirical facts of reasons as constitutive of action to be brought to bear on philosophical argument; evidence will be able to replace armchair reasoning.

Philosophy notwithstanding, and leaving aside the meaning of cause, our enquires here will provide evidence on what reasons are in a particular way. As we say, our interest is not in reasons as objects of philosophical inquiry so much as reasons as lived phenomena, as felt practices, bound up, as we have already noted, in the accountabilities of everyday life and, in this regard, to be understood with respect to their role in that life. This is, thus, a social scientific concern; one to do with evidence. This concern will, we hope, lead us to furnish data for asking just what the plural forms of reasons might be - 'causal' in some instances, having other relations to actions elsewhere.

In short, our evidence will help open up some of the natural richness and variety of reasons, as part of the skeins through which people account in their daily lives for what they do and how they understand those doings. The reasons that we seek are the vernacular of making sense, and this includes how people make moral sense of themselves and others, of their actions and their shared doings. Though we might only want to explore reasons to Skype, we think our enquires will point towards how people understand the lives they lead in terms that makes sense to them, with regard to reasons that are applicable to what they are about as they understand those doings and for which they use their own language to articulate. Reasons are central if not exclusively the property of this language. It is to exploring the empirical and conceptual implications of this position that we now turn.

3. Whether this will ever lead to a full-blown revival of interest in his work is another question. 


\section{Evidence in everyday reasoning about Skype}

Our explorations are based on transcript data from two separate sets of interviews with families and friends who used video applications like Skype. The first were conducted in 2014 and were concerned specifically with traditional Skype-like video calling - with Skyping as a verb. They sought to uncover the everyday reasons used to account for and reflexively organise doings with video connections. The second set were conducted in 2014/2015 as part of a study of a new form of video connection that piggy-backed on some of the technical infrastructure of the traditional Skype application. Here, too, the concern was with everyday language and its categorisations. But the concern was more specifically with how language terms are used prospectively to organise what doings a new application might encourage or entail (see details in Rintel et al. 2016). Crudely speaking, we sought in these second interviews ways of exploring linguistic routes to new technological concepts.

Be that as it may, these interviews were audio taped and transcripts of these are used here, in this paper. With this evidence, we organise the paper as follows. The first empirical section will present some transcript evidence, and this relates to how 'reasons to do something' are articulated in particular, socially organized ways. In this instance, reasons for Skyping offered at the start of an interview have a certain form intended to focus subsequent questions and topics in that interview. Their temporal or sequential placement at the start of the interview is vital to their function as an account. They are designed to foreshadow subsequent acts with some prefatory work that identifies the grounds for what would be 'normal reasons to Skype' that might be inquired into later on. In being so placed, they also articulate the interviewee as a person able to articulate ordinary reasons in ordinary, that is to say, apposite ways. This is a form of 'doing being ordinary'.

This will lead to consideration of the category work done in the interviews related to how the term Skype can be used. We show how this use orders understanding and topic related to Skype, and, in particular, helps describe a field of relevant behaviours that are sanctioned as appropriate for Skype related endeavours. These descriptions justify these actions while accounting for them. We then turn to show how this accounting work also characterizes what is to be thought as the right, normal and typical people who use Skype.

We then turn to see how these formulations help scaffold a space in which the detailed nature of the communicative affairs of the interviewed subjects can be produced. This creation is only possible if the general nature of what Skype is for (or entails) is a given, a starting point, something to contrast or highlight, say. We shall see, in this final empirical section, that these particularities are elaborated through 
reference to other equally commonplace notions about social affairs, though not in this case to do with communications technologies; rather, these have to do with the kinds of relations that these communications articulate - between mothers and daughters say, or 'just' between friends. This allusion to participation status or participation frameworks (Goodwin 1981; Harper, Watson \& Woelfer, this volume) points towards how the social world as made up of known relationships that are used as a resource to make sense of how the world in which those relationships matter or might be changing. To see how you are losing touch with parents presupposes you know what parents are and how they are normally kept in contact with, for example, and thus helps you articulate why you may seek to use or avoid Skype. In light of this, we end with some remarks on the question of identity, and how people express their unique circumstances even as they cast themselves as typical, normal, and just like anyone else.

\section{Why Skype?}

As we say, our data is taken from interviews the ostensible purpose of which was to 'talk about' video calling, Skyping being the representative synonym for this. The subjects were fully apprised of this when they agreed to interview. Hence the interviews were characterised by a general structure - after introductions, the first open-ended question was posed, namely "Do you Skype and if so why?" This was followed by answers - as one would expect. Though these did not always end up in the affirmative (some saying that they used to use Skype but had reduced the frequency of doing so, for example), what is worth noting is that most began with assertions about what were self-evidently the kind of reasons that any normal, everyday person would have for using Skype. As we shall see later, these very reasons were sometimes deployed at subsequent points in the interview to explain how, in some particular case, Skype (or alternates), was not used. For what we will see is that the self-evident reasons for using Skype provide a contrast set reasons for not using Skype, to not video calls at all.

So, before we get to that, let us look at some of these ordinarily reasons that the subjects expressed when initially asked. The two following excerpts are taken from the start of different interviews, and for the sake of length, are merely the relevant sections from the transcripts. In each, the subject has been asked why they might Skype; this is the first question after introductions in the interviews. Their answers seem platitudes, obvious things. But why they are such platitudes, and why they are offered at this point in the interview, is what makes them interesting. 


\section{Segment 1.}

When my Mum is on she'll say "Oh I want to see your new room" or the "things you've put on your wall" and stufflike that.

\section{Segment 2.}

[Skype] experiences are really precious to me because I love to see the kids and they can't use the phone by themselves but my sister can get them started on this.

It is important to note something that is so obvious that it might not otherwise be remarked upon: that these are positioned immediately after a call for reasons, i.e. a question, and that they are economically expressed. By that we mean that these answers are not long - only two lines. One could easily imagine considerably greater length - after all, and since we have already mentioned him, think of Wittgenstein's Brown Book (1964). This starts with a simple question. His was 'What is the meaning of a word?' but it goes on for 74 pages. Hanson, meanwhile (ibid) expends a section of his book solely on the meanings of the word 'cause' and its agnates. We asked what might be though of as a simple question, too: Do you Skype? And while it might be simple, as with the questions that Hanson and Wittgenstein ask, one could imagine a whole litany of things being offered in answer. To conjecture: these things might include, say, cost, obligation, compulsion, desire, routine and so on. But we don't find such a list. Nor do we find any elaborate theory; one doesn't hear a kind of notion that one might read in, say, social psychology, that holds that seeing (through Skype say) brings people some kind of intimacy and similar; nor by way of further example, do we hear any of the kind of philosophical theory to do with using the visual to enable simulation of the 'other's mind' (Goldman 2006).

This is not to say that such general reasons or lists of reasons are never invoked and deployed when people are asked 'Why Skype?' But is only to warn against the analytical presumption that all reasons (and lists of them included) pertain for on each and every occasion. We don't see that here; we see, in contrast, a straight to the point manner, an economy of expression that seems to imply, in that economy, that there is no need to elaborate, to make lists or theories; that the kind of reasons one can offer here are 'what any one can agree to'. They are, as we have noted, platitudes. But in being platitudes, they are not saying this is a feature of the facts in question, as it is a feature of how commonly those facts are agreed to. 'Everyone knows this about Skype', these answers are implying. They are also showing that, in the selection of this type of answer, the interviewees are sensitive to what they are being asked to do. They are offering reasons that are, as we say, 'to the point' when to the point alludes to the when of their presentation. One needs to understand these answers partly in terms of substance (what they list or don't list), and partly in terms of their placement in the interaction at hand. 
The issues we are wanting to highlight here are not to do with, say, a potential contrast between an expert doing an analysis versus a layman, one thus lengthy and the other therefore short; it is not Wittgenstein's intellect versus an everyday 'folk knowledge' to which we are alluding (a point that Goldman makes). The shortness of the answers and their placement, when they were offered, we want to claim shows élan on the part of the interviewees at trying to structure the organisation of what is talked about in interview in their own turns at talk. This seems a lot to claim from the economy of these answers. But by eschewing undue length, abstraction, theory, these answers are seeking, we suggest, what Harvey Sacks called "doing being ordinary". By this is not meant a claim about social categories, ordinary folks and unusual folks, but rather a technique of showing, in one's conversational utterances, that one knows and is alert to what the conversation at hand is about and where it is likely to go. One is ordinary in one's skills at understanding the situation, and this is shown in part by being sensitive to what is a suitable answer to a question at that moment in time might be.

Part of the ways in which this is done is through showing recognition, in one's answers, that some things are glosses, summaries that can be offered because of where and when they are offered. As we have already alluded, the term Skype works as a gloss standing on behalf of a whole raft of practices; practices that competent users of Skype routinely know and take-for-granted. ${ }^{4}$ It seems to us that the brevity of the interviewees' answers turn on their expectation that their interviewers will, at some later point in the interview, seek to propose a theory about why people Skype; to unpack this gloss. The interviewees do not know this for certain at this moment, but one might presuppose that they night expect this as a real possibility. After all, why convene interviews if the interviewers do not want to develop a theory or something similar, a list of reasons to Skype perhaps? Certainly this is what many marketing researchers would seek when they interview, even if this was not the goal in our interviews. Of course, the interviewees do not know for certain that theory and lists are, in fact, where the interviewers want to go, so one might adduce that their economical answers reflect a desire on their part to not overly prejudge

4. Additionally, a gloss is itself done through a set of related glossing practices (Garfinkel and Sacks 1970) - Skyping being part of being in touch, being friendly, and so on. To un-gloss the proper name Skype, in addition to its relations to these other glosses, might involve reference to, say, clicking on a contact's name, indicating whether one wants to use both audio and video aspects with that contact, waiting for the dial tone, directing the focus of the video if that has been selected ("Oh, I want to see your new room or the things you've put on your wall and stuff like that"), such that the gloss of the word is as it were unpacked and made topical to the talk itself. The transformation of this proper name into a verb, to Skype, inherits and trades upon then the proper noun gloss: which is itself a derivative that bears an agnatic relation to the original one. 
where the interview would go later on. By doing so they can avoid making that future work somehow tangled up with prior utterances - as in "you said earlier", etc. One might say it quietens down how their initial assertions might be treated, so as to make easier steps later on in the interview, and allows, too, the true purposes of the interviewers to unfold.

Doubtless, one might want to present more such examples to make our case about these matters more robust, but given constraints of length we hope the point can be accepted; reasons are constituted in part by their substance and in part by their sequential position in talk; both also offer routes for subsequent actions. They mutually elaborate both the moment of their utterance and future moments when further utterances might be offered to further this initial characterisation.

Our basic point is one that is now well evidenced in the empirical analysis of talk, from Harvey Sacks onwards: that the sequential location of an utterance is important. We are not offering anything new here. But what we are offering is an aspect of 'reasons', and what we are seeing is that reasons are to be understood, in part, by where they are placed and why they are placed at that moment in some interaction. The reasons we are seeking relate to Skype, but there is a general lesson: reasons are socially organized in their articulation, in when and how they are brought to bear in talk.

If what we say is right, this does not mean we should treat reasons as these as merely preliminary. On the contrary, they are constitutive; they help set up what might be the full set of reasons. For there is a subtlety in even these terse answers that might seem at first paradoxical, given what we have just said. This has to do with the fact that, despite the economy of words, in these answers there is a set of practical reasons to be found: the answers are more than yes or no. If, as we note, we can see in these answers 'operations on a question' (Sacks 1992; i.e., appropriate responses that invoke the question in the answer), we see these as achieved through volunteering reasons that have a special character. They are presented as if they are so ordinary and so obvious, so easily stated, that the one who holds those views is thus, like the reasons themselves, ordinary, not unusual, but one who knows how the world is, why Skyping is and how it is done. This way of putting these reasons is such that no-one would dispute those reasons if they, too, share the same ordinary world. Consequently it is not just reasons about Skyping that are presented as easily said and readily understood, but thereby also the persons who state then and who hear them without complaint. These reasons are offered as normal reasons for normal people. They are thus being used to co-opt both parties in the interaction, in this case the interviewee and the interviewer. The subjects are saying 'normal people have normal reasons', these are normal reasons, you, the interviewer, should recognise these are such. The interviewees are implying, that is, and in the way their construct their answers, that if a person didn't 'know these things about Skype' (i.e., reasons to Skype), it would not be Skype that would 
need investigation, it might be them - the person. Something about their nature leads them to be different and this might warrant some questions. This doesn't just apply to the speaker. Just as the economy of initial answers allows later topics to arise, so at the same time the 'content' of this economy constrains these topics so they don't end up allowing the conversation to lead to enquiries into how odd or unusual the interviewee is. The interviewees present themselves as ordinary and use this to allow the interviewers to assert the same through their responses. And they do so as to allow questions about other matters, since the identity of both interlocutors can be taken as a given, not a topic.

Of course being in an interview context might imply that the one doing the interview is just that sort of person to whom such inquires might apply - that they are 'odd' and that this is the reason why they are asking about Skype. But by presenting reasons to Skype in this fashion, and typically at the outset of the interviews, an opportunity is presented for the interviewee to do what Schegloff called a 'membership analysis' on the interviewer to find out if this is the case. Since the interviewers typically did concur with what the interviewees stated (though space precludes us showing that), these individuals were then able to see that the interviewers, like them, had a common notion of what Skype entailed. This was bound up with shared notions not only of what the technology could do but the ordinary reasons that ordinary, unremarkable people would have to use that technology. Though the answers might be short, they can now be seen as loaded with performative value.

Further illustration of performativities can be seen in the third segment, below.

\section{Segment 3.}

I: Okay. If someone came up to you and said "What are the benefits of [Skyping]" what would you answer?

S2: Hmm I would tell them that if you're in some kind of long distance relationship it's really the easiest way to have a real good meaningful conversation with someone you want to talk to and it..it.. just it's above and beyond the phone like leaps and bounds I think, it's I really think it's a lot better than that so that would be my argument that it's better than the phone (laughs).

I: And is that because you can see the other person?

S2: Yeah it well you know it's some of the audio quality I think too the sound on the headset is a lot better than um the uh the phone quality even that in and of itself I thought was pretty good but definitely the video was fantastic too.

I: Was there anything about the video in particular that just you know any moment or any time when you thought "Wow if I'd been on the phone I would have missed that, I wouldn't have seen this so this is what makes videoconferencing really excellent"? 
S2: Yeah definitely like if she wanted to show me something she was working on Uni-wise or what she was wearing or anything like that you know there's a way to describe that over the phone but it's never going to come close to actually just being able to see what she's talking about, and I definitely think that's the case.

What we see here is that understanding what Skyping means is a jointly achieved interactional accomplishment, one that the interviewers and the interviewees were fully party to and which they both jointly built up. As we remark, one can imagine lots of researchers with an alternative perspective complaining about this collaboration between themselves and their subjects, but this would be to ignore what we have noted is a key feature of social action: that it is built on common understandings and know-how. Thus, for an interview to suggest that he or she did not understand Skype as the interview subjects did would have affected how the interview would unfold, and would have set up a competitive attitude of the kind we might term 'methodological irony'. It might make the interviewers seem odd to their subjects, casting them not as people who wanted to explore the world as it is known to be, but as people who didn't have that shared experience. If the interviewers suggested this, it might have short-circuited the interview; stopped it there and then. But the interviews did not come to a seizure precisely because the interviewers acknowledged a shared world. The normative preference for an agreement that one finds in speech exchange systems of many kinds are, then, a resource for interviewers in this case, as they might be for any other, but this agreement is about a world as known in common. The performativity of reasons then, is partly related to how they can be agreed, as 'ordinary reasons'.

\subsection{Particular reasons}

In having made this agreement, having noted that both interviewer and interviewee participated in a life in which reasons for Skyping are a 'known', the interview talk could move on. And moving on is what nearly all the interviewees did - in collaboration with the interviewers of course. Both wanted to get to other matters - nuances in the doings of Skyping that would merit the interview, whatever they might be.

In the bigger transcripts part of the motive for moving on in becomes clearer in a very crude sense. For the bulk of the interviews were about these nuances, to do with reasons not to Skype given reasons to Skype.

Before we can turn to those, we need to note that part of the way these 'reasons to talk about' have the shape they do is that they too are foreshadowed in the initial responses to the question, "Why Skype?" Take the 1st segment, above; here the interviewee says that, with Skype, their interlocutor ('Mum'), can demand to see something, and demand that can be satisfied given that Skype is being used. They 
don't say that they use Skype because it affords, say, an analogue to the face to face encounter, nor do they offer the explanation that it is free; one could add other possible reasons, just as the reader might too (indeed we offered more above, it will be recalled). In this respect, the sense or meaning of Skype is being given by a set of what one might say are uniquely-referring identifying statements (Searle 1963; Watson 1981) - that Skyping is, for example, about seeing. The gloss, the noun, goes hand in hand with a referral point such as this.

In this manner one can hear these statements about seeing as intentional, as a method, given in the way of the telling, that articulates the notion that 'seeing' is the thing that is salient if you want to understand Skype. And in offering this in an utterance at the start of the interview the interviewees are not offering this as a contributory fact that might be added with others to make some kind of arithmetic; on the contrary, these remarks, and importantly, their placement, are designed to assert a way of understanding what the value of Skype is, namely, an orientation to action that one can assume is the normal manner with it. Seeing is key, seeing is the first thing one might say about Skype; and this is indeed the first thing that this respondent does say in Segment 1.

Without spending too much on this point, the interviewee does the same in Segment 2, as does the subject in the 3rd but with some elisions. As should be clear, though, and the third highlights this, while seeing is presented as somehow the primary reason, other reasons are also invoked - ease of use in the second for example, good sound in the third. But all segments show that the type of relationship between the users of Skype is also a source of 'reasons to' do a Skype call. In the first, the mother-child relation is given as causal grounds, in the second, an auntniece relation (or so it would appear), and in the third, a relationship that is, as the saying has it, a 'relationship'. Something about relationships is normatively linked to seeing, in other words, and thus is fodder for 'reasons to Skype'.

One can put this more formally. References to reasons to Skype involve treating selected reasons in terms of categorisation devices (Maynard 1988; Sacks 1974; Fitzgerald \& Housley 2015), ones that invoke courses of action and relevancies, ways of doing something in and through Skype. One uses Skype so as to see, in these instances. And of course, this seems obvious - as it should do, given what we have said about Skype being familiar to all. Yet we are also learning that Skype is to be used given the relationship between the parties involved. One doesn't Skype a stranger - or one could, but in these accounts that's not the normal pattern, not what everyone knows as the kind of normal thing one does; one Skype's people one has a relationship to, and seeing within the call articulates that relationship. 


\subsection{Reasons to interrogate}

Even with the limited sets of evidence we have already, we can see that on any specific occasion of Skyping, there will be a particular nesting of categories, one having to do with ways of looking and the other bound up with orthogonal categories of human affairs, the senses of the body (sight) being married to legal and moral connections (marriage, courtship). If they are family relations, say, there is a notion that visual solicitation may be entailed, with parents asking, for example, how their offspring are doing and getting satisfaction to that request by seeing that this is so: "He looks fine" is the kind of thing one can imagine being said. In other words, their rights are manifest through an act of seeing. For another example, if it is a partner that one Skype's, then 'meaning' is foregrounded in such a fashion that it is implied to be delivered through sight, 'meaning' presumably pointing towards a partner's expression, and so on. One might say that this seeing in the general sense and leaving these instances aside, the feel of gaze, a lingering, intentional looking that can only be done with propriety and not offence through a willingness on both parties. The point is that the categorial organization of the relationship defines the order of practice that one seeks in any given Skype connection; and given the categorisation this is, this in turn is wed to the other category of action; in this case, to see. And beyond this, these connections are ones that anyone would know, anyone that is familiar with 'doing Skype'; gaze, in this sense, is normal - though endowed with social consequence, it is a normal consequence.

It is important to note here that seeing, being subject to the gaze of another, is thus being described not as manifest in what the eyes behold but in what the eyes allow the parties involved to 'see-and-speak-about', given the categorial cast to the relationship in question. It is, in this respect, a way of looking that embodies rights to look purposefully, with intention; we might say interrogatively, to put it strongly. These purposes articulate the relationship between the persons, highlighting what is to be looked for, what is accountable, what is irrelevant in that relationship. These categories are mutually explicative of each other, at least in this context. Thus to see is to see something with a set of rights to see given the relationship; this is why we use the words 'gaze' and 'interrogative'. Conversely, a relationship between persons can be used to explicate what might be looked at as part of that relationship. What is to be seen in Skype (or in talk about what can be seen in Skype) is potentiated by the order of the relationship that already pertains between those involved. Consequently, those socially-categorized as 'mothers' may be allocated rights to see things about the offspring's life that, say, those categorized as 'acquaintances' may not - and, of course, vice versa. The interrogative gaze is a set of rights not available to all. 
In our evidence, this seems key to how Skyping is made accountable in talk. It is through a structured and situated combination of mutually-related, mutually-elaborating categorisations of persons - 'membership categorisations', in ethnomethodological or conversation analytic parlance - that the experience of using Skype on particular occasions is accounted for and comes to have its 'interrogative' feel; it is through the inter-operation of these categories, seeing and relating, that action in Skype is constituted and reflexively organized. ${ }^{5}$

Additional membership categorisations can, of course, be added to these in ways we shall discuss shortly, but for now we can note that, in summary, it is via routinely seen-and-spoken membership categorisations that an occasion of Skype usage presents itself as a having normal, typical, and routine manner, as having the form it does. This is very important in terms of demarcating the ways that one can explain action and the reasons that might or might not 'motivate' it. For it turns out that, in the ways it is accounted for, Skyping is not chosen as a function of, let us say, psychological preferences or desires, but through the purposeful and adroit management of, putting it simply, choice; choice about an intentional framing that comes to be shared and understood. Interlocutors might not agree on whether such intentions are well chosen with regard to Skype, but see those intentions in its use, and certainly talk about those intentions as grounds to turn to Skype on, just as they use them as grounds to turn Skype off. It is also the case that these ways of reasoning can lead people to avoid Skype altogether. It is to the topic of why one would not Skype or would seek to avoid Skype that we now turn.

\subsection{Reasons as a particular kind of feature of social interaction}

Our evidence is suggesting that, while there might be a set of known-in-common normative preferences around Skype usage, these norms are best thought of as accountably applied, ways of describing and hence organizing how to talk about Skype. That this is so implies that there are few if any absolute constraints on what people do when they Skype. Norms as we see described in the accountability of Skyping suggest that people can use Skype for other reasons, for reasons which are

5. One should add that any given membership categorization can also be part of what in other contexts has been called 'visibility arrangements' (Watson 2005). Membership categories are for seeing as well as for talking and therefore are particularly felicitous implements for a seeing-and-talking situation such as that fabricated when 'doing Skype'. One can speak, then, of the visual availability of membership categories, and this visible dimension includes 'category-bound predications' such as those that, say, identify 'mother' as having the right to ask to look at things that persons identified through other membership categories might well not be able to ask to see. 
not 'normal' - but if they do so (i.e., act in un-normal ways) they might very well need to account explicitly for doing so.

What we are noting is the nature of reasons here: they are not determinants of conduct, but are ways of describing and directing activity at the same time. This allows those reasons to be seen as guiding as well as excusing; inviting what is right and allowing what is unusual by providing a framework for the explanation of both - conduct that is normal, conduct which is unusual.

Moreover, we are seeing that these reasons are furnished with an additional property: that they assert that those who hold these reasons are normal, usual, typical, unexceptional in themselves. They act according to these reasons or invoke them to explain their own contrastive or exceptional conduct (e.g., 'I didn't use Skype normally'). Thereby they convey that they are persons whose nature itself should not be brought into doubt by dint of their acting on those 'unusual' reasons.

In short, reasons here are shared, reasons that normal people would have and which are negotiated, acknowledged and recognised anew each time Skype is talked about or engaged in by members of that community. This is an everyday accountability we are talking about; reasons are part of what is talked about even as they make the world have the shape it does. Reasons are of the world just as much as they describe the world.

It is important to note that we are not saying that certain types of people have these (everyday, accountable) reasons and others don't. We are emphatically not drawing a line between those who are within a community and those who are without, members and non-members. This is the kind of argument about reasoning that Velleman proposes in Foundations for Moral Relativism (2013). Though Velleman claims his arguments derive from Sacks, it is clear he does not understand the point that Sacks was making when he coined the phrase, doing being ordinary. It was not to label moral communities; it's a method for making shared sense. Likewise here: invoking reasons and implying the kind of persons who holds them makes the persons thus invoked members of a shared world and this is done for the practical purposes of creating shared understanding for the particular activities at hand - in this case, for interview talk. Such characterisations allow that talk to unfold in an effective manner, without distracting discussion about, for example, who knows what and who does not. Nor does it imply different communities, some that hold these reasons and others that don't. This is not how this talk with and about reasons works; certainly not in this case.

Furthermore, these reasons are also to be understood in reference to the placement, at certain moments within the context in question. The reasons mentioned above were presented at the commencement of these interviews, as we noted. These reasons are factual in the sense that they are substantive grounds for action, but are 
to be understood in their manner, in the scope or scale of their detail and in the way they are evoked and rendered relevant at a particular juncture in interaction; they are above all praxiological products bound to the time and place in which they are made to 'work'. Reasons are in this sense a kind of doing done at a certain time; facts about Skype are temporally located statements to put it another way. What we are saying is that the reasons one finds in an interview are to be understood as such, as artefacts of that social practice, with a time and a place constitutive of them; they are not transcendental entities, Kantian Universals. The reasons we are looking at are properly understood as features of social organization internal to the events in which they are deployed and which they help organise. This does not deny their facticity, their concrete nature, but shapes their valence: how these reasons can be cast as and understood through their role in matters of social arrangements. Consequently, and to point towards current philosophy, these kinds of reasons are not examples of, to cite him again, Velleman's (2013) relativistic 'social mores', reasons and facts that are little better than localised agreements. These reasons, the ones we are looking at, matter and are real, even though the sense of them, their applicability, is interactionally demonstrated and achieved. They are situated but not 'relative' because of that.

\subsection{Reasons not to Skype}

Be that as it may, and as should be becoming clear, a concomitant feature of 'reasons to Skype' is that their shape outlines what might be 'reasons not to Skype' (or to avoid Skyping). Their shape also helps outline the ways in which such reasons themselves might be articulated. Here we are thinking of the arrangements of categories and descriptors that provide for normal reasons not to do something. One should not think of reasons to do something and reasons not to do something as like an equation. Both are orders of articulated reasoning, presented in sequences of action that variously entail invoking properties of each other whilst also marshaling and depending upon where and when they are deployed - on local contingency and accordingly, other facts or reasons that can be seen to pertain at that moment in time; that situation. To present reasons for some action is itself dependent upon when it is the right time to bring those reasons to account just as it means knowing when those reasons can be used to explain why they don't apply in some case - for when one chooses not to Skype, there may be some particular arrangement that makes all the normal givens inapplicable, or which creates an amalgam of concerns that alters the reasoned interpretation of 'what is appropriate' to one where not Skyping is the right thing to do. 
For example, and given what we have said above, one could 'reasonably claim' that a person might want to communicate about their intentions regarding emotional life. If so, 'seeing things' at the remote end of a call or showing things off at one's own end might not be salient to such matters; love, lust, desire, yearning may not be best articulated with showings. So one might well therefore not choose to make communications about such topics via Skype. Instead, one might offer that as a reason why one does not want to use Skype. That is to say, given one's topic, one can explain to one's interlocutors your preference for, say, email, voice, or whatever.

The move here is not strictly about things that can be seen and those things which cannot be, so much as orders of appropriate attention where seeing is only a constituent, and probably only a minor one if relevant at all, for certain types of topics and doings in acts of communication. Things which can be seen might not be so salient to communicate one's intentions if those are related to ones emotional life we are saying, but the same might apply to other things too: take one's career choices. This topic might well not be a suitable candidate for Skyping. It can thus also be an accountable reason not to Skype.

Of course, it may be that the career depends upon some physical attribute, muscle size say, and so it might be that showing such is something that would aid in the talk. But again, selecting Skype for such talk implies what might be the topic, even if the talk is already identified as about intentions. For even these we are suggesting might imply see-ables, things to gaze at and wonder on - the size of muscles say, the rippling of well honed stomachs; all this is bound to the purposes (often given via membership categories) at hand. So if a Skype call is made then the referencing of the seeable doesn't have to negate attempts to focus on one's 'adult intentions', but it means that raising such matters can be treated as an accountable matter - as in 'Why are you referring to that (whatever it might be) if you want to talk about your intentions - why are you showing me your biceps?'

\subsection{Reasons as a vocabulary for accountability}

The long and short of it is that reasons for doing something that are commonly understood are also mechanisms for, or vehicles for, elaborating the space in which those reasons operate; a context or gestalt that can be explored to account for the unusual or especially constrained nature of the reasons at hand, the topics that interlocutors want to focus on. This broader context of reasons can help explain too, or provide a resource for, reasons to act which are beyond the bounds of that normal space.

It should come as no surprise, therefore, that the kinds of reasons our interviewees offered for not Skyping took all sorts of forms. Consider Segment 5. 


\section{Segment 5.}

SD: We can't Skype with Jon's parents cause his mum is very glamorous, and um she hates it, she hates, yep.

I: Because she thinks she doesn't look good on camera?

SD: Yes. And my mum feels like she doesn't look good on camera but she still does it, because she wants to see the children. But Jon's mum won't do it. Once we were here and her best friend, Jon's mum was visiting, and her best friend called up on Skype, and as soon as she started the call she went upstairs to do her hair, and she was really cross afterwards.

Looking good, being glamorous, being seen when one did not expect to be, all these are accountable reasons to 'resisting' Skype. As we see they are also reasons for telling people off, for 'being cross afterwards'.

Accounts that allude to the moral or other consequences of the visual, and relatedly to what is often described as matters of self-consciousness, are commonplace in research in video-mediated communication; most often, though, such research treats these reasons as indices of something other, invasions of privacy, say, or matters to do with self-esteem that could be measured through surveys. But the reasons we see here are intrinsic to the lived experience of Skyping and of talking about Skype. These are the reasons of the everyday, felt life. These are reasons people can act on; they are accountable and don't need measuring or external elaboration. Such possibilities are not relevant to their nature. This does not mean these reasons are somehow impoverished, lacking in colour or depth, complexity. Because they are used in the everyday doesn't mean they are shallow.

For example, in Segment 5, above, we should notice that some of the reasons for someone not wanting to Skype are ascribed in the third person. They are not reported in first-person, as avowed by that person herself. That is to say, 'looking glamorous' is not a motive that the mother in question is here avowing; it is a motive others impute to her. This is an important distinction for it shows how wide the landscape of reasons might be and the diverse relationships between instances of action and the reasons for those actions.

We might recall Sandis's (2012) argument that the philosophy of action must allow plurality of reasons. Here we find proof that plurality of reason is part of the stuff of everyday life, and the delicate and nuanced relation between reasons and action. After all, to say of another that she looks glamorous is not just to impute intentions to her, it also guides the eyes of the beholder: one looks for observable proof of that glamour, it becomes a target of our interrogative gaze from the outset of a Skype call, for example. And besides this, the speaker who uses the term glamorous may have his or her own category-related reasons for using this formula; perhaps they want to present their mother as glamorous to their friends and thus 
imply that the mothers' of their friends are not so glamorous. The situation is, as it were, motive-rich.

These nuances are important to note, for it draws a distinction between reasons in everyday life and the character of reasons as being plural, a goal we noted Sandis wants in current thinking in the philosophy of action. For while it might be that in the philosophical discourse and indeed in sociology of reasons (where reason is often cast as motive - see Sharrock and Watson 1984), reasons are often presented as singular, essential often. In contrast, our examples are suggestive of how reasons are better understood as 'accountably sufficient' to let the action in question continue without too much enquiry whether they are singular or multifarious. Their number doesn't matter. It's their applicability that does. And key here is the fact that this is not to be located only in the nature of the reasons at issue. The adequacy of reasons is related not just to what they label or identify but to the manner of their deployment in action. This has to do with such matters as the economy of their invocation of the circumstances that govern their applicability, what this implies about subsequent orders of questions and inquiry, and, consequent on that, when they were said; where they were placed in the interaction.

All this we have discussed. This does not mean that reasons can never get out of hand, so to speak. On specific occasions they do, and this is also tied up with the kinds of reasons they might be as well as their praxiological placement. One might find glamour a puzzling reason for example and, having heard it, one might perhaps raise reasons for a dissenting view. This might entail pointing to multiple motives, say, the conflict between the facts of a person's glamour and the desire of another to see it being considered, as we have already mentioned.

Having said that one should not forget either that whether reasons are singular or multiple, in important respects they are "seen but unnoticed", as Garfinkel puts it, treated as grounds for common understanding such that the activities in hand can get done. As we saw in the opening accounts on the interview data, facts about the persons being interviewed are treated in a 'quiet' way not because they are right or wrong; the reasons that these people have, or which can be used to understand their motives, are treated thus so as to allow the interview to move along. Reasons might or might not exist, but some reasons have to be taken for granted, ignored if you like, if subsequent reasoned, purposeful action is to be achieved. In this sense, reasons are an outcome, an accomplishment of their endogenous role in interaction and when diligently placed, allow other reasons to come into play later on, at a future moment. 


\subsection{Reasons beyond sight}

We are saying that reasons are intrinsic to accountable action, but we are also saying that reasons do not constrain action; they help sensibly organise it and they do so by allowing the management of relevance. If we have said that the interrogative gaze is the assumed motive for Skyping, and that this can be used as a foil to bring to bear other reasons, then some of these other reasons have to do with the unseeable.

Consider: in some interviews, reasons were offered that pointed to the 'self' rather than to the seen other or to objects that both and all could see. Much of what is seen and assumed to be seen when Skyping is described in these accounts as somehow stopping access to a much more richly imagined felt life, a world that cannot be seen by the visual torch-like affect of the interrogative gaze, and this is often said to be 'the self'. This phrase is not always used, but adequately conveys the reasons we are pointing to, as Segments 6 and 7 show.

\section{Segment 6.}

IL: I have a couple of best friends that I use Skype with but I hate to [Skype]. I don't need to see the face of who I'm talking with. I love the phone but I prefer I don't see their face because it feels, I dunno, quite impersonal, I don't like it-

I: Impersonal?

IL: Yeah it's not real. You know if I use the phone I can have an image of my friends, so I don't need - I feel quite violated, violating, like invading some space that doesn't belong to me. If you and I meet, have a coffee, walk and talk, that's fine. If we have a Skype, I feel somehow I don't belong with you [if I see video]. So I prefer just [using it as a] phone [...] I don't like- like you are in your room, I know you have a picture of Star Wars there I don't care, I don't feel comfortable in a videoconference at all.

\section{Segment 7.}

IJ: And it's also kind of awkward if-you look at them in the video and you kind of look at each other, it's kind of, emotional for me, like it's very, I don't know like it, [sigh], I feel like if we look at each other we might-we might not know what to say, but if we don't look at each other we might have a larger freedom to talk about things.

Things that can be seen are, we find here, set up as a contrast pair over those things that cannot be seen, and this is used to explain and account for what is implied to be a loss of control over topic. This is also explained as likely to affect the purposes of a communication - the reasons for it. It would appear from these segments that these reasons can be difficult to shape or convey, even though, and as we say, normal reasons to Skype provide a resource for such elaboration. 
One of our interviewees expanded on reasons why she did not always Skype by using some accounts of activities in which Skype was not used. She drew analogues as we see in Segment 8. These analogues help her explain and give credit to her reasoning about how to understand the intersection of visual matters as topics with the framework of interaction and relevant things to talk about implied in a family relationship and the topics that seem relevant or appropriate to such relationships. As we put it earlier, these two concerns, the visual and the relational, mutually explicate each other in situations of choice.

Below, the interviewee explains that having something to see jointly with a mother can sometimes contain or trap potential topics to those see-ables. This comes at a price, she instructs us to understand, as we see in Segment 8:

\section{Segment 8.}

IJ: So, I've had-sometimes when I- when I'm home and I'll be driving a car and my mom's sit by me, and we can talk about, um, you know, very meaningful conversations. So, it's very hard to talk to her face to face about some serious topic, about what I'm thinking, about my philosophy for life, or, for love, you know, just sounds like so stupid, so artificial, but when we don't look at each other, it's sort of, it's something like we can actually treat each other as an adult, or, or individual, right, it's kind of like, you know, I'm not your, I'm not your daughter, or you're not my mom, you're not superior than me, or something, that we can actually have a conversation as we are two equal adults, or, or individuals, it's, it's easier that way, to don't look at each other and be reminded that, oh, you're just a kid, you're my daughter. But when I look at her, as I said, um, I think my imagination will be limited to talk about surroundings, talk about what I see, talk about, you know, mundane stuff.

Though the phraseology here might seem tentative, evidently more improvised than she might prefer, what is brought to bear nonetheless is an elaborate set of notions about how the world is organised in and through talk, and how this talk is the crucible for negotiating what the world as a shared phenomenon will come to be. This world, the one she wants, includes mental landscapes. Skype is a technology that is described as somehow inhibiting access to this field; the mental landscape is beyond the interrogative gaze. In this we see how key features of how Skype is ordinarily understood and accounted for are combined with other matters to make sense of unique actions and circumstances. The limited field of visual seeing is married with the moral field of a person's inner life. 


\subsection{Reasons as located acts}

This might seem a long way from our explorations of initial reasons why Skype is said to be used - where the visual was linked to the relationship in question. But this example recapitulates those initial premises, those gambits at a start of an interview, so as to allow more depth and colour about particularities, about how this person deploys Skype in her life. We see, crucially, that the problem of Skype has to do with the problem of relationships, her relationships in particular. We find that the relationship in question is one where one party, the daughter, seems intent on trying to assert some control over the other, her mother; or, rather, we find she is wanting to achieve this but finds it hard to do. Thus she is telling us that being able to control topic in acts of communication is crucial to the enactment of herself, but this is constrained by the apparent control over topic allowed to her mother by dint of her categorisation status as 'mother'. This shows itself in actual acts of communication - in Skype calls say.

It might be helpful to put this another way. The account explains how someone can negotiate the management of topics, and explains how this is easier to do when one person is not subject to the gaze of another when those two persons have a particular relationship. Somehow the gaze of Skype allows one person to have control over what the other might say. This is bound not just to the technological medium, but to the relationship of the persons involved. Given that relationship, Skype lets one see too much, one might say, even though seeing has nothing to do with it - not in this instance, not directly.

One can explore this point so as to show how the general is used to frame the particular, and how this is echoed in the ways in which reasons to do something are presented and sequenced and how this in turn, points towards something that seems enormously larger, how the person in question is trying to alter the world. In Segment 8, parent/offspring relations are being characterised as being governed by a rule that holds that, whatever their age (mutatis mutandis), offspring are 'answerable' to their parents: daughters to mothers; children to parents; kids should respond to mum and dad, be accountable to them, act on their directives (see for example Aronsson \& Cekaite 2011). Having stated this arrangement of facts, reasons can then be brought to bear to explain why this person doesn't want to abide by those first set of reasons. In other words, the order of reasons sets up the nature of those reasons and their relationship to actions and the world more largely.

We see that the choice-making activities of this person, the daughter, her ways of explaining why she would not use Skype, are meant to reflect her attempts - her desire - to re-balance her relations with her mother, to changes the facts of the world - the reasons people have for acting. This ambition is understandable by anyone, we would suggest, as normal behaviour, as reasoned behavior, since the 
way they are presented, and this includes when they are presented, sets them up as facts that anyone would know. This is in turn allows this woman to justify another special kind of fact, her desire, her wish that her mother 'wasn't my mother'. Again, this reason seems reasonable given its placement, how it is brought to bear. She articulates reasons so that reasons make sense; that can convey what she is about and why. Her problem, though, and one we are meant to sympathise with, is that knowing these reasons, having these reasons, cannot make some things happen - here indeed a reason cannot become a cause if that labels only things that really occur (See Leist 2007, particularly his review of Davidson's “Action, Reasons, and Causes").

In attempting to move toward a more analytic understanding of (in the present study) such 'choice-making procedures' we are pointing to some salient elements of those practices whilst also noting that their meaning, their functional significance, is related to a broader pattern which, following Garfinkel's interpretation of Gurwitsch's notion, one might call a 'gestalt contexture'. Such contextures are 'autochthonous'; that is to say, naturally occurring, organized, temporally located, situated in real contexts of choice and interaction. As Liberman $(2013,43)$ puts it, these are phenomenal fields, patterned arrays of details where the salience of the arrangements and hence their pertinence is achieved though participants' methodical work in the production of those arrangements. This is how the dwelling spaces of existence come to have the form they do - through the work of people making the reasons they have get the shape they do, 'dwelling in reasons' (Ingold 2102).

These dwelling places are characterized in large part by the parties involved and their relational 'framework' that is itself manifest in their language management through time, their praxiological skills at talk (Goodwin 1981). As we have noted, many of our interviewees methodically brought to bear in the accounts of 'reasons to Skype' their relationships with others, parents especially. These relations were explained as constitutive of their strategic and practical orientation to Skyping. Their articulations about how to manage topic with these relations were central to this. This in turn was bound inextricably to what we have called the interrogative gaze that Skype enables and which our subjects treated as a given fact about Skype.

This notion of gaze, and likewise various frameworks of social connection, mother/daughter, relationship persons and so on, should not be thought of as constituting a structure through which people act or account for their actions. Nor do these matters frame what people can and cannot do. It is rather that these features, the power of gaze, the salience of family connection, all come out of the work that our subjects undertake when they talk about Skype, and doubtless come into play when they do in fact Skype. They are, if you like achieved phenomena.

That this is so may be contrasted with the original formulation of the concept 'participation framework', found in Duranti and Goodwin (1992). Here, 
frameworks such as the ones we describe are viewed as like a social structure that "align[s] speakers to hearers and actualize a state of discourse". As our samples show, our respondents make the participation framework, the structure of their relation with their relations, come to be a relevant feature of their interactions in the ways they talk about and, in the way they constitute, reasons for action. Part of this performative work entails setting up some reasons as common, as reasons to easily agree to, so that more specific and probably more unique reasons can then be understood in specific, particular ways.

This work is partly done through the placement of reasons, their economy, their relative order, and what they foreshadow and prejudge. Thus we have seen that one set of reasons constitutive of how to understand Skyping has to do with the common place that you use it to see; that this is offered is not as a reason that might be tested, but as a reason that both the utterer and the hearer can easily and uncontentiously agree to. If this agreement is made, if no complaint about this is offered, then a next stage in constructing a set of reasons might be embarked upon, such as ones to do with family relations. If these, in turn, are agreed to, then the peculiarities of a speaker's particular relations can be brought to bear in the talk; the ground for this specificity has been set. Amongst other things, these grounds also avoid any question that the person doing the accounting is peculiar, and not ordinary. But this is a move not to assert this as a fact, but to focus attention on other matters: the relationship one, and related to that, how this manifests particular experiential facts in interaction in Skype.

What we are saying is that such things as a framework of participation are products of instructive talk. One should not be distracted by the apparent form of this framework from recognising it as an outcome of talk, or rather, the interactional production of a situated, collaboratively produced understanding intended to allow that interaction to achieve particular ends. In this case, these ends are not to offer facts about the world, but facts about the world that can be understood as reasons that explain why one of the parties in the interaction acts as they do in the world at large. What is at issue is understanding a person; invoking frameworks of relationship between persons helps convey that understanding.

There is great skill in this. In Segment 8 we see that while there is considerable astuteness in the way that the issues are formulated, there is also an astuteness in their ambiguity. This interviewee does not assert that questions of topic are dictated by family structure, nor that seeing things is certain to crowd out other topics. On the contrary, she is trying to explain, in the interview, that being what she wants to be, and articulate that as she sees fit, is a hard thing to do: she has to negotiate her way through a shared currency of techniques and systems of propriety that are based on knowledge she knows is shared both by the interviewers and her mother; knowledge about the arrangements of the world and what doings in the world 
afford - such as when one Skype's. She is stating that one cannot deny that mothers have rights over daughters, that one cannot deny either that when one's mother looks you in the eye it can make one still feel like a rabbit in car headlamps. She uses her knowledge of a world in common to explain her unique problem in this regard. Her goal is to offer us grounds for compassion about her circumstances. It's her she is describing, through the lens of the world she inhabits.

In this she seems to be stretching the ways that language can be used to convey a sense of herself. She evokes the ordinary to point towards the aching of her human spirit as it drowns in the details of daily interaction with parents, in circumstances that inhibit the breaking out from those patterns. As the philosopher Laugier puts it (alluding to Emerson), one might say this is a person who is a 'victim' of the way expressive arrangements unfold and how demanding they are in terms of how they need to be used and how they often seem indirect in their manner $(2000,117)$. But nevertheless what we see is that she does skillfully deploy words to articulate her reasons and what she thinks might be her way out of her predicament. Whether she will ever manage to make her way out is another matter. What is sure is that she does manage to convey that predicament. She might be homeless, but this person is astute with the mechanics of talk to convey the uniqueness of who she is (or wants to be).

\section{Conclusions}

In short, there is intelligence in the way that reasons for Skype are talked about. Often this intelligence seems as profound as anything one will find in everyday life even if the reasons that assert that intelligence seem, at times, almost ineffable, as the struggle for clarity in Segment 8 seems to suggest. Difficulties such as this notwithstanding, empirical inquiries into how reasons are talked about and embedded in real worldly action show that reasons are not best treated as theoretical entities, nor as triagable lists, nor yet as simply sets of causes. What we find are reasons that are presented delicately, appropriately, in terms of time and location, all of which shapes the extent, form, interdependence and salience of those reasons. We see also, that reasons can be used as measures of individuals; their motives, their competence, their social grace, as well as their looks, their capacities to see, their willingness to notice and to perform, to be gazed at and to gaze in return. All this constitutes the reasoned rhythm of twenty first century, technologically mediated communications.

Our purpose in this paper has been to examine some of the important features of this reasoned rhythm. Our task has not been to show whether people can say wrong or right things about Skype but rather to examine how people invoke Skype 
as a categorizing device in their utterances that results in that category, 'Skype', coming to be a relevant organizing matter in their affairs. Or, to put this another way, we have examined how invoking Skype and Skyping is a sense making device that can be relevantly brought up in spoken efforts to accomplish a world known in common with fellow interlocutors - friends, family, even interviewers. Skyping brings people together in more ways that just the visual; its use as a term in language makes the world one in common, fabricated through that word - along with many other words, many other categories of course.

Skyping is to be seen through the prism of language and language praxis, and it is through language that one can see how Skype comes to matter. We might draw on analogy here with the subjects of an article by Garfinkel et al. on the activities of professional astrophysicists (1981, 131-58). These astrophysicists have reached the pinnacle of their educational and professional careers, but it is not that status that matters to Garfinkel and his colleagues. The work that Garfinkel et al. are interested in is how these professionals need to do linguistic category work. This work entails fitting empirical evidence to appropriate categorisations and descriptions; evidence to words and through words back to evidence that does the trick it needs to - persuades all involved in that setting that what they think they are talking about is indeed real, a thing worth talking about. The methodical work that Garfinkel et al. describe relates to how prospective descriptions of a 'to be found object' (an optical pulsar), are tied, step by step, in a retrospective and prospective accounting, in utterances of professional talk, to emerging evidence.

This is a much more dramatic setting than everyday Skyping but the lesson is that here too, in this everyday practice, people cannot describe some aspect of a Skype call without plausible reason to do so, and similarly, cannot summon another to participate in such a call without using ordinary, everyday utterances and topic management procedures to make those activities sensible and accountable, as ordinary things to do where the reasons for them are thus agreed to and understood by those involved. Using Skype, talking about Skype is then like the discovery of some astrophysical entity: it as to be done through the in-situ application of particular 'consequential' categories in turns at talk - consequential in terms of 'reasons for a Skype call' or 'reasons for why it is to be avoided'. While Garfinkel and his colleagues showed that through talk science comes to be done, so it is that through talk that Skyping comes to be a relevant matter for everyday life, understood and undertaken in particular ways to achieve particular ends - everyday ends to be sure, but ones whose nuance and manner is various and always unique: the work of friendship, for example, even in the more constrained and patterned maneuvers of mother and daughter connections.

Hence, while 'scientific discovery' might be the business of the highly regarded, the work entailed in it is thus equal in technique to the work of those who talk about 
and use communication technologies, Skype, Face Time, Google Hangouts. There are skills to be found, we are saying, in how terms about the 'facts of everyday life' (in this case technological ones but they could be any 'facts about' or 'features of' the world) get used in demonstrably competent ways to make those facts part of the performativity of human collaboration (see Lynch 1993 for an exploration of the diverse forms of this).

Using the word Skype isn't just a matter of word-smithing; it is always purposive, intentional, a practical but serious matter done with reasons in mind - even if those reasons are not stated clearly or in summary form. Getting this performativity wrong will result in weakened ties, in friends drifting away, in hurt families, in life's loves being lost in the unstructured routines of communications without thought. It has been our task of this paper to explore just how this thoughtless might show itself, and how its opposite, thoughtfulness, can be shown in decision making about Skype. Skype might be a commonplace, but its use matters: it shows the reasons people have for love, for friendship, for family as well as the reasons they have for changing these things.

\section{References}

Adato, A. 1980. "Occasionality as a Constituent Feature of the Known-in-common Character of Topics.” Human Studies 3: 47-64. doi:10.1007/BFo2331800

Aronsson, K., and A. Cekaite. 2011. "Activity Contracts and Directives in Everyday Family Politics." Discourse and Society 22 (2): 137-54. doi:10.1177/0957926510392124

Davidson, D. 1963. “Action, Reasons, and Causes." Journal of Philosophy 60: 685-700, repr. in Action \& Events, 1980: 3-20. Oxford: Oxford University Press.

Duranti, A., and C. Goodwin, 1992. “Editors' Introduction.” Rethinking Context. Cambridge: Cambridge University Press.

Elias, N. 1969 (or 1939). The Civilizing Process. Vol. I. The History of Manners. Oxford: Blackwell. Fitzgerald, R., and W. Housley. 2015. Advances in Membership Categorisation Analysis. London: Sage. doi: $10.4135 / 9781473917873$

Garfinkel, H. 1967. Studies in Ethnomethodology. Englewood Cliffs, New Jersey: Prentice Hall.

Garfinkel, H., M. Lynch, and E. Livingston. 1981. “The Work of a Discovering Science Construed with Materials from the Optically-Delivered Pulsar." Philosophy of the Social Sciences. 11: 131-58. doi:10.1177/004839318101100202

Garfinkel, H., and H. Sacks. 1970. “On Formal Structures of Practical Actions.” In Theoretical Sociology: Perspectives and Developments, ed. by J. C. McKinney, and E. A. Tiryakian, 337366. New York: Appleton-Century Crofts.

Goldman, A. 2006. Simulating Minds: The Philosophy, Psychology and Neuroscience of Mind Reading. Oxford: Oxford University Press. doi:10.1093/0195138929.001.0001

Goodwin, C. 1981. Conversational Organization, Interaction Between Speakers and Hearers. New York: Academic Press. 
Hanson, N. R. 1972. Observation and Explanation: A Guide to Philosophy of Science. London: George Allen and Unwin.

Harper, R. 2010. Texture: Human Expression in the Age of Communications Overload. Cambridge, MA: MIT.

Harper, R., D. Randall, and W. Sharrock. 2016. Choice. Cambridge: Polity Press.

Harper, R., D. R. Watson, and J. Woelfer. This issue. “The Skype Paradox: Homelessness and Selective Intimacy in the Use of Communications Technology." In Special Issue of Pragmatics, Interpersonal video communication as a site of human sociality, ed. by Harper et al. Pragmatics 27 (3):. Amsterdam: John Benjamins.

Ingold, T. 2011. Being Alive: Essays on Movement, Knowledge and Description. Abingdon: Routledge.

Hume, D. [1739-40] 1974. A Treatise on Human Nature, 2nd Edition, ed. P. Niddich. Oxford: Oxford University Press.

Laugier, S. 2000. Why We Need Ordinary Language Philosophy. Chicago: University of Chicago Press.

Leist, A. (ed.) 2007. Action in Context. Berlin: de Gruyter. doi:10.1515/9783110898798

Lynch, M. 1993. Scientific Practice and Ordinary Action: Ethnomethodology and Social Studies of Science. Cambridge: Cambridge University Press.

Madianou, M., and D. Miller. 2012. Migration and New Media: Transnational Families and Polymedia. London: Routledge.

Maynard, D. W. 1988. "Language, Interaction, and Social Problems." Social Problems 35: 311-334. doi: $10.2307 / 800590$

Miller, D., and J. Sininan. 2014. Webcam. Cambridge: Polity Press.

Papacharissi, Z. (ed.). 2011. A Networked Self. London: Routledge.

Rintel, S., R. Harper, and K. O'Hara. 2016. “The Tyranny of the Everyday in Mobile Video Messaging." Proceedings of CH'16. San Jose: ACM Press. doi: 10.1145/2858036.2858042

Sacks, H. 1972. "An Initial Investigation of the Usability of Conversational Data for Doing Sociology." In Studies in Social Interaction, ed. by D. Sudnow, 31-74. New York: The Free Press.

Sacks, H. 1974. “On the Analysability of Stories by Children.” In Ethnomethodology: Selected Readings, ed. by R. Turner, 216-232. Harmondsworth: Penguin.

Sacks, H. 1992. Lectures on Conversation, Volumes I \& II. Malden: Blackwell.

Sacks, H., and E. Schegloff. 1979. "Two Preferences in the Organization of Reference to Persons in Conversation and Their Interaction." In Everyday Language: Studies in Ethnomethodology, ed. by G. Psathas, 15-21. New York: Irvington Press.

Sandis, C. 2012. The Things We Do and Why We Do Them. Basingstoke: Palgrave. doi: $10.1057 / 9780230360105$

Searle, J. R. 1963. "Proper Names." In Philosophy and Ordinary Language, ed. by C. E. Caton, 154-161. Urbana: University of Illinois Press.

Sharrock, W. W., and D. R. Watson. 1984. "What's the Point of "Rescuing Motives"?" British Journal of Sociology, 35 (3): 435-51. doi:10.2307/590974

Velleman, J. D. 2013. Foundations for Moral Relativism. Cambridge: Open Book. doi: 10.11647/OBP.oo29

Watson, D. R. 1981. "Conversational and Organisational Uses of Proper Names: An Aspect of Counsellor-Client Interaction.” In Medical Work: Realities and Routines, ed. by P. Atkinson, and C. Heath, 91-108. Farnborough: Gower. 
Watson, D. R. 2005. “The Visibility Arrangements of Public Space: Conceptual Resources and Methodological Issues in Analysing Pedestrian Movements." In Communication and Cognition, Special Issue, ed. by M. Ball, 38 (3/4): 201-229.

Watson, D. R. 2014. "Trust in Interpersonal Interaction and Cloud Computing." In Trust, Computing and Society, ed. by R. H. R. Harper, 172-198. Cambridge: Cambridge University Press. doi:10.1017/CBO9781139828567.012

Wittgenstein, L. 1953. Philosophical Investigations, 4th Ed. trans G. E. M. Anscombe, P. M. S. Hacker, and J. Schulte, Oxford: Blackwell.

Wittgenstein, L. 1964. The Blue and Brown Books. Oxford: Blackwell.

\section{Authors' addresses}

Richard Harper

Social Shaping Research

Cambridge CB3 9DY

United Kingdom

richard@socialshapingresearch.com

Sean Rintel

Microsoft Research

Cambridge CB1 0FB

United Kingdom

srintel@microsoft.com

Rod Watson

Telecom ParisTech, Nice-Sophia-Antipolis

1 rue Claude Daunesse

Nice-Sophia-Antipolis 06904

France

r.watson339@bitinternet.com

Kenton O'Hara

Microsoft Research

Cambridge CB1 0FB

United Kingdom

kohar@microsoft.com 